\title{
Virtual Power Electronics: Novel Software Tools for Design, Modeling and Education
}

\author{
Janos Hamar Non-member (Budapest University of Technology and Economics, hamar@elektro.get.bme.hu) \\ István Nagy Non-member (Budapest University of Technology and Economics, nagy@elektro.get.bme.hu) \\ Hirohito Funato Member (Utsunomiya University, funato@cc.utsunomiya-u.ac.jp) \\ Satoshi Ogasawara Member (Hokkaido University, oga@ist.hokudai.ac.jp) \\ Octavian Dranga Non-member (James Cook University, octavian.dranga@jcu.edu.au) \\ Yasuyuki Nishida Member (Nihon University, nishida@ee.ce.nihon-u.ac.jp)
}

Keywords: dynamic modeling, e-learning, software, nonlinear systems

This paper discusses two initiatives, called Inetele project and Yoto project. The Yoto project is a cooperative work, originally with the participation of universities from Japan and Hungary that is nowadays gaining ground in Australia as well. The main profile of the project is teaching power electronics and motion control, furthermore to support engineers by embedded high-speed design tools. Within the framework of the Leonardo da Vinci program of the European Union (EU) the Inetele project incorporating eight universities from eight member states is aimed at developing multimedia software for teaching Electrical Engineering. The paper is concerned with a small fraction of the project relating to nonlinear systems. Some key concepts of these e-learning projects are as follows: to popularize the electrical engineering sciences, to promote the high quality academic education of the electrical engineering field, to support the regular industrial vocational trainings, to increase the flexibility of the education regarding the time and the location, to mitigate the geographical and regional inequalities by making accessible up-to-date research \& development results and to support the education of handicapped students. Simple frameworks have been elaborated, providing control, navigation and display functionalities at both projects. The architecture forces the separation of the real technical content appearing in modules from the display and control, following the rules of the general principle in software engineering called Model-View-Controller (MVC).

1. Nonlinear Dynamics (Inetele Project)

The e-module presented in this paper contains two chapters: the

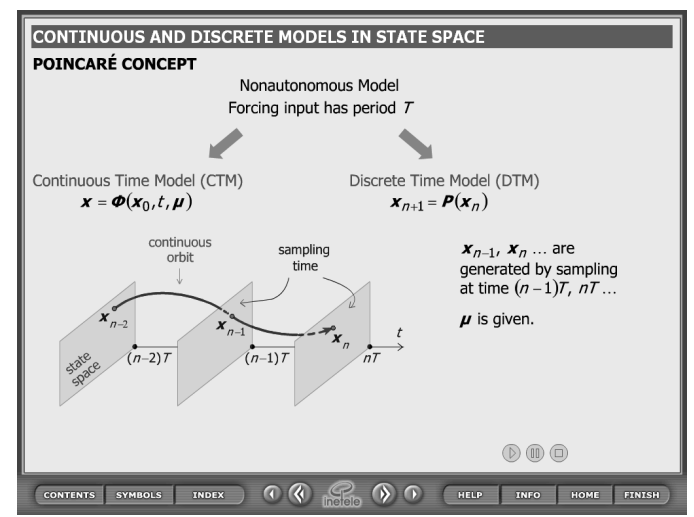

Fig. 1. An example screen explaining the Poincare concept
Linear and Nonlinear Part (Fig. 1).

The main sections in the Linear Part are Introduction, Application of Linear Dynamical Models in Control, Linearization of Power Electronics Converters, Linearization Using State-Space Averaging. The main sections of the Nonlinear Part are: Continuous and Discrete Models in State Space, Regular States, Quasi-periodic State, Maps, Manifolds, Homoclinic and Heteroclinic Orbits, Bifurcations, Routes to Chaos, Chaotic State, Applications in Power Electronics.

\section{Power Electronics (Yoto Project)}

Two modules of the Yoto project are also being discussed in this paper. The first one comprises the Steady-state Operation and Classification of DC-DC Converters, focusing on the basic step-down, step-up and step up/down configurations. The technical and mathematical principles are explained, followed by new interactive modeling software that helps understanding of the operation of those circuits. The second module keeps emphasis on the Dynamic Modeling and Linearization of DC-DC Converters. Continuous and discretetime approaches are presented in order to determine the linear models of the converters at different values of the input-, circuit- and control parameters. The modules contain a lot of animations and numerous highly interactive tools.

An example screen is shown about an embedded control-design tool in Fig. 2, facilitating the automatic calculation of the discretetime model of a boost converter, visualizing the operation point and the location of the poles and zero of the system in relation to the unit circle.

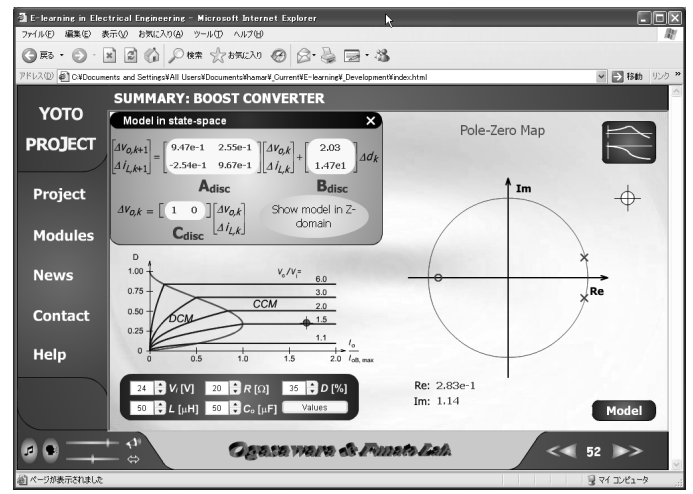

Fig. 2. Interactive modeling tool: example for the boost converter 


\section{Virtual Power Electronics: Novel Software Tools for Design, Modeling and Education}

$\begin{array}{ll}\text { Janos Hamar } & \text { Non-member } \\ \text { István Nagy }^{*} & \text { Non-member } \\ \text { Hirohito Funato** }^{* *} & \text { Member } \\ \text { Satoshi Ogasawara*** }^{*} & \text { Member } \\ \text { Octavian Dranga**** }^{* * *} & \text { Non-member } \\ \text { Yasuyuki Nishida }^{* 5} & \text { Member }\end{array}$

The current paper is dedicated to present browser-based multimedia-rich software tools and e-learning curriculum to support the design and modeling process of power electronics circuits and to explain sometimes rather sophisticated phenomena. Two projects will be discussed. The so-called Inetele project is financed by the Leonardo da Vinci program of the European Union (EU). It is a collaborative project between numerous EU universities and institutes to develop state-of-the art curriculum in Electrical Engineering. Another cooperative project with participation of Japanese, European and Australian institutes focuses especially on developing e-learning curriculum, interactive design and modeling tools, furthermore on development of a virtual laboratory. Snapshots from these two projects will be presented.

Keywords: dynamic modeling, e-learning, software, nonlinear systems

\section{Introduction}

A detailed survey on the state of development of E-learning curriculum in Electrical Engineering with a special attention to the fields of Electrical Drives and Power Electronics has been compiled in (1). This survey focuses on the relation between the conventional education and the e-learning supported, multimedia-based education. The conclusion is that it is good time for moving from teaching-oriented curriculum design to learning oriented one. The latter one helps making the education more attractive for the university students and for the engineers, participating in vocational trainings. It requires a rather careful design of the curriculum, appropriately conveying the dynamical structures and interactions

Based on "Virtual Power Electronics: Novel Software Tools for Design, Modeling and Education" by J. Hamar, I. Nagy, H. Funato, S. Ogasawara, O. Dranga and Y. Nishida, which appeared in the proceedings of the 2007 Power Conversion Conference-Nagoya, (C)2007 IEEE.

* Dept. of Automation and Applied Informatics, Budapest University of Technology and Economics,

Goldmann Gyorgy ter 3, 1111 Budapest, Hungary (EU)

Phone: +36-1-463-1165 Fax: +36-1-463-3163

** Power Electronics Laboratory, Dept. of Electrical and Electronic Engineering Utsunomiya University,

7-1-2, Yoto, Utsunomiya 321-8585

*** Division of System Science and Infomatics, Graduate School of Information Science \& Technology, Hokkaido University, Kita 14, Nishi 9, Kita-ku, Sapporo 060-0814

**** School of Engineering, James Cook University, Townsville QLD 4811, Australia

Phone: +61 747814376 Fax: +61 747815177

${ }^{* 5}$ Energy Electronics Lab., Dept. of Electrical \& Electronic Eng., College of Engineering, Nihon University

Tokusada, Tamura-machi, Kouriyama 963-8642

Tel \& Fax: +81-24-956-8788 by animations. The paper also points out that e-learning is a lot more than on-line learning. "It is a sophisticated learning system that keeps the student skilled, provides just in time information and facilitates meaningful, directed collaboration".

One of the first initiatives in this field was carried out by J. Kolar and U. Drofenik at the Swiss Federal Institute of Technology Zurich, in Switzerland. The Interactive Power Electronics Seminar (IPES) is widely known ${ }^{(2)(3)}$. It contains interactive e-learning tools for power electronics and electrical machines: signal theory in power electronics, theory of three phase systems, dc-dc converters, several types of diode and thyristor rectifiers with different supply and load conditions, dc drives, power factor correctors, resonant converters, one and three phase converters, matrix converters, Vienna rectifier, thermal problems in power electronics, heat transfer models, fundamentals of electric and magnetic fields, etc. In recent years the number of the available interactive animations has continuously been increasing.

The physical quantities (voltage, current, flux, etc.) in the electronic circuits are very often not directly perceptible, only through some measuring equipments. At the design of the animations usually one of the most complicated tasks is the visualization of the electric quantities and characteristics. An interesting approach to visualize the operation of electric circuits is shown in (4). The novelty of the animations is that instead of using the conventional 2D representations of the electric circuits, 3D ones are applied. The role of the third (z) axis is to present the voltage alterations in the circuit.

An e-learning curriculum was prepared in the frames of a Tempus Joint European Project with the participation of three European universities ${ }^{(5)}$ (contractor: University of Manchester, Institute of Science and Technology). The content 
includes animations and interactive surface to explain the operation of the transformers, DC-motors, -generators, induction machines, synchronous machines, brushless machines, stepper motors, reluctance drives, actuators, linear motors, heating and cooling, bridge-inverters, etc. The home page ${ }^{(6)}$ offers Java-based interactive animations for explaining the current and voltage sharing among resistors connected in parallel and in series, respectively; furthermore it explains the behavior of resistors, inductors and capacitors in one phase networks. The basic series and parallel RL, RC and RLC circuits are also investigated. The animations are completed with the basic equations necessary to solve similar examples. Unfortunately the text is included only in Japanese language. Further interesting results of this area were published in (12)(17). The current paper discusses two initiatives, the Yoto project and the Inetele project. The Yoto project is a cooperative work, originally with the participation of universities from Japan and Hungary that has later been extended by an Australian University as well. The main profile of the project is teaching power electronics and motion control, furthermore providing engineers with embedded high-speed design tools. The name Yoto comes from the name of a district in Utsunomiya city. The Inetele project (Interactive and Unified E-Based Education and Training in Electrical Engineering) has been carried out within the frames of Leonardo da Vinci Programme sponsored by the European Union ${ }^{(8)(9)}$. With the participation of altogether twelve European institutes, new multimedia based curriculums were developed for teaching Electrical Engineering. The main fields of interest were: CAD in electrical engineering, electrical machines and apparatus, microelectronics, industrial and power electronics, electric drive systems and their applications, control of technological processes, influence of converters on environment and power quality improvement. The paper is concerned with a small fraction of the project relating to nonlinear systems.

The concept of both e-learning projects was settled around the following key ideas:

- To popularize the electrical engineering sciences.

- To promote the high quality academic education in the electrical engineering field.

- To support the regular vocational trainings of the companies for the qualified engineers.

- To increase the flexibility of the education in terms of time and location.

- To mitigate the geographical and regional inequalities by making accessible up-to-date research \& development results.

- To support the education of handicapped students.

Simple frameworks have been elaborated, providing control, navigation and display functionalities to both projects (Fig. 1). The architecture forces the separation of the real technical content appearing in modules from the display and control, following the rules of the general principle in software development called Model-View-Controller (MVC).

The main graphic user interface is shortly presented for the Inetele project. The outlook of the animated screens is the same at all pages as shown in the figures below. At the bottom of all animated screens a menu is visible. The meaning and function of the buttons are as follows:

contevis Displays the contents of the multimedia module;

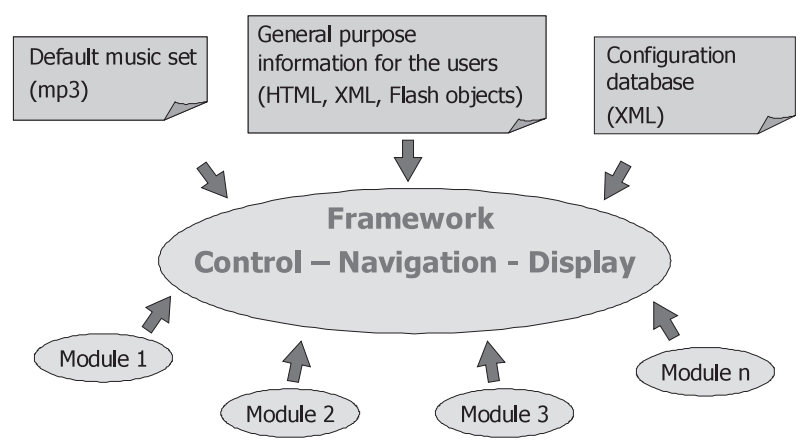

Fig. 1. Basic architecture

srmвoLs Displays the index of keywords of the module;

(4) Shows the previous subchapter of the module

(1) Shows the previous chapter of the module

(1) Shows the next chapter of the multimedia module;

(D) Shows the next subchapter of the multimedia module

MELP Displays help;

номе Shows the main (home) screen of the module;

Finrst Ends browsing the multimedia module.

Further menu points are: (1) Animation is activated; (10) Animation is paused; (D) Initial state is reinstalled; (DD) Play the animation step by step; (JII) Music is turned on-off; (III) Sound is turned on-off. The outlook of the screens of the Yoto framework looks to be different at first sight, however the same functions can also be easily found there. In the subsequent chapters several modules will shortly be discussed about power electronics and nonlinear dynamics.

During the development of the frameworks and the modules, Macromedia Flash Technology was extensively applied at the common and interactive animations, furthermore HTML, CSS, XML and XSLT were also widely used. The contents are being tested and translated to additional languages now at both projects with the involvement of numerous universities. They are currently available freely for testing purposes on request, however they will soon be available via Internet.

A general expectation can be sensed in university circles all over the world that there is a severe lack of unified e-learning system to teach electrical engineering, especially focusing on power electronics and nonlinear systems. The main contribution of Yoto and Inetele projects to the former initiatives can shortly be summarized as follows:

- Framework-based approach, that is, the main control and display functionalities are solved uniformly in a separate layer behind the content. The curriculum can flexibly be added/removed as separate modules, following several predefined rules and standards during the design. University students are often pretty motivated to use and to contribute to the content development. The high level modularization facilitates the segmentation of the activities to work-phases, thus, the segmented sub-tasks can be identified as individual semester projects for inquisitive students.

- Multimedia tools are thoroughly involved. Interactive 
tools are mixed with explanation text and speech all over the screens, highlighting the premises, background, the mathematical and physical grounds and the applications. Hence, it gives an overall view about the topics in question; putting forward the learning based education in comparison with the teaching based one. None of the other initiatives described in the beginning of this paper provides such a wide multimedia learning toolset.

- The module-contents can easily be localized. The framework provides wide flexibility to add textual and vocal components in any language.

- The basic system can be extended to remote (virtual) laboratory, where trainees can make measurements on real laboratory devices from a remote location via Internet ${ }^{(10)}$. The integration of this feature to the Yoto project is currently in progress.

\section{Power Electronics (Yoto Project)}

2.1 Steady-state of DC-DC Converters The module primarily focuses on the classification and the steady-state operation of the step-down, step-up and step-up/down converters. The principles of dc-dc conversion are presented, including the technical background that are necessary to understand the essential relations among the input and output voltages and currents. The main classification methods of these converters (Fig. 2) are followed by the basic assumptions considered. These screens contain numerous interactive animations.

The shape of the choke current and semiconductor current waveforms as well as the average and the peak values of these currents are also essential in the practical converter design, especially at the selection of the circuit components [e.g. magnetic core, diode and the semiconductor switch (mostly MOSFET, or IGBT)]. Since these converters belong to the family of stepwise linear circuits, the equations are explained for each sub-periods of the corresponding converter. A screen snapshot on the sub-periods and the relations for the currents can be seen in Fig. 3.

The summary part of the module includes highly interactive tools both to help the understanding of the operation and also to assist the design process (Fig. 4). These tools contain the circuit in the top left corner, where the actual path

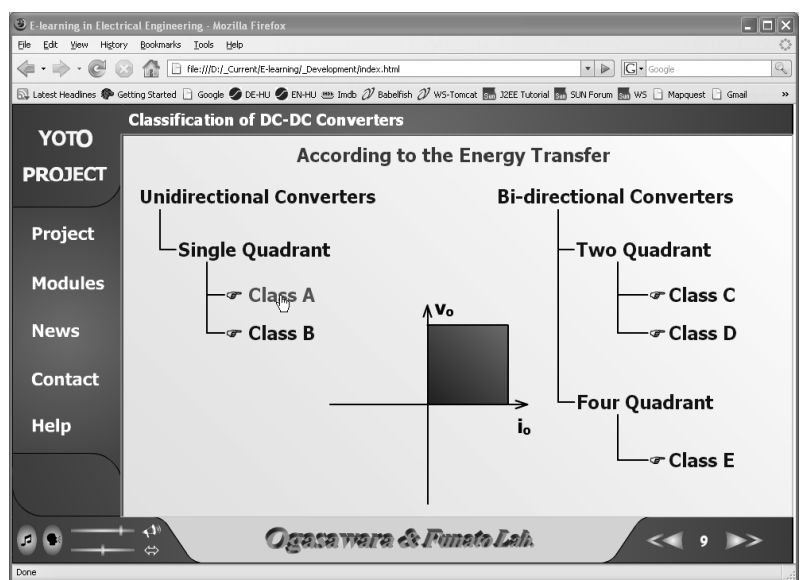

Fig. 2. Converter classification according to energy transfer of the current is shown in an animated manner. The most essential waveforms, that is, voltage and current time functions are placed on the right hand side in the figure. It includes the switching signal of the controlled switch and the inductor voltage in the first two rows. In the third row the choke current, the input and the output current can be displayed by clicking on the appropriate radio button.

Finally the output voltage waveform is shown in the lowest row. In case of the buck converter an optional way is to show the reverse voltage across the diode, pointing out the role of the low-pass filter formulated by the LC circuit.

While the vertical (red) guide-line is moving left and right over the time functions, the state of the switch in the top left circuit changes accordingly.

\subsection{Dynamic Modeling of DC-DC Converters}

Following the introduction, the module focuses on two particularly useful modeling approaches, the continuoustime averaging approach and the discrete-time iterative mapping approach. The averaging approach effectively removes the time-varying dependence from the original time-varying model and produces a continuous-time state equation that contains no time-varying terms. The module describes the modeling process, in which the state equations of all the possible stages are first written down, and the final model is simply the weighted average of all these state equations. The weightings are determined from the relative durations of the

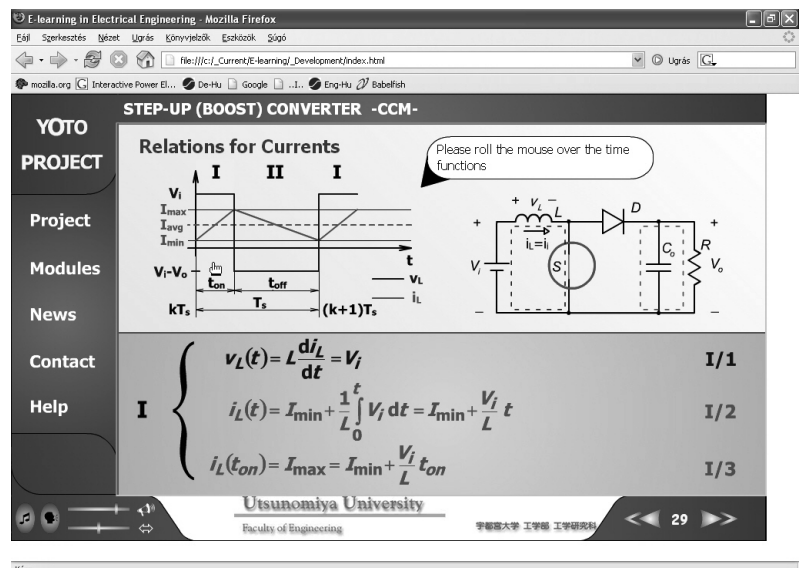

Fig. 3. Currents waveforms: boost converter, CCM operation

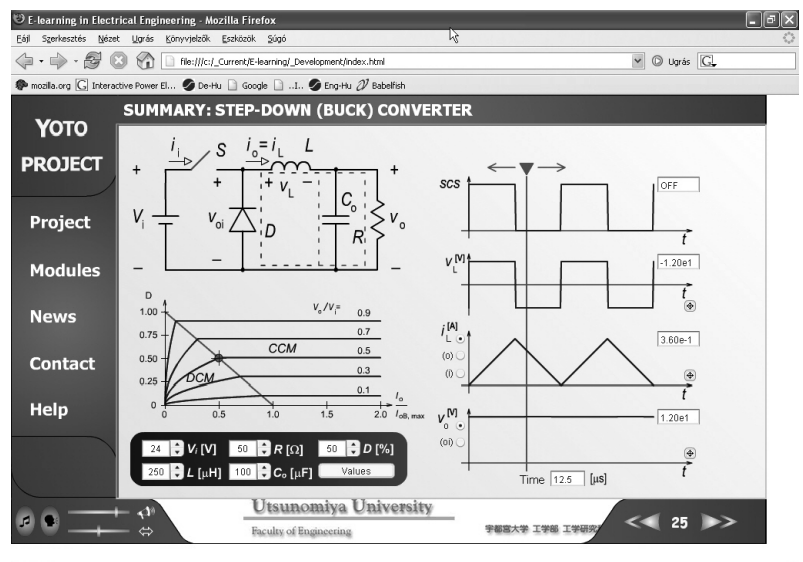

Fig. 4. Interactive tools: buck converter 


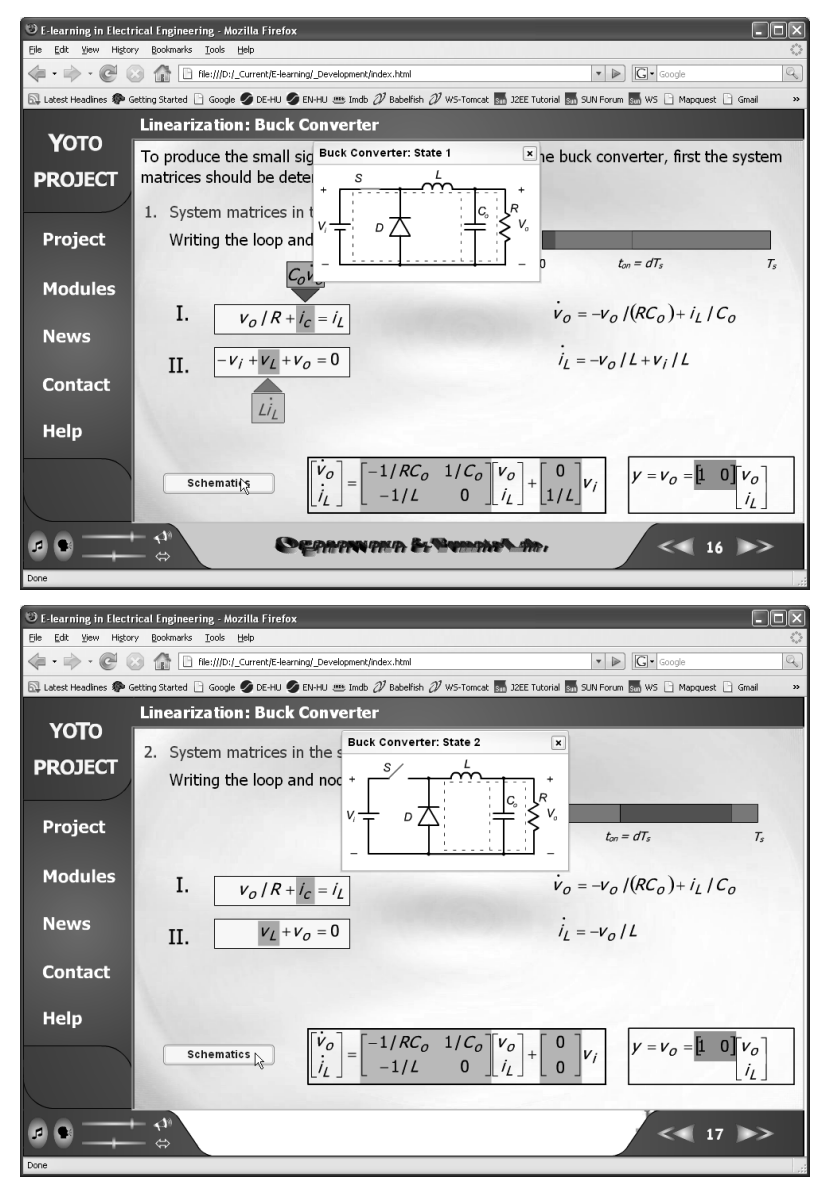

Fig. 5. Identifying the switching subperiods

stages, which are illustrated through the red-colored "flow" of time (Fig. 5). The next step of the modeling is the assumption and corresponding substitution into the equations for each of the new variables of a constant (dc) nominal component and a small perturbation component (ac).

Finally, the system is linearized around the steady-state operating point by expanding the equations, neglecting second-order perturbation terms and subtracting the respective steady-state equations. This part of the module, describing the continuous-time linear modeling by state-space averaging, ends by expressing the control-to-output transfer function, obtained by taking the Laplace transforms of the linear differential equations representing the small signal (ac) behavior of the converter (Fig. 6). The general state space averaging method is shown for the step-down (buck), step-up (boost) and step up-down (buck \& boost) converters. The detailed process is shown for each converter yielding the state space matrix equations and the small signal transfer functions.

Summarizing the continuous time modeling of dc-dc converters, interactive tools were developed (Fig. 7). They facilitate the easy change of the input voltage, duty ratio, load resistance, choke inductance and output capacitance. Linear models both in the state-space and in the s-domain are immediately calculated and shown on the basis of the adjusted parameters. It can be well traced, how the model alters as any of the parameters varies. This functionality is available by pressing the "Model" button in the bottom right corner

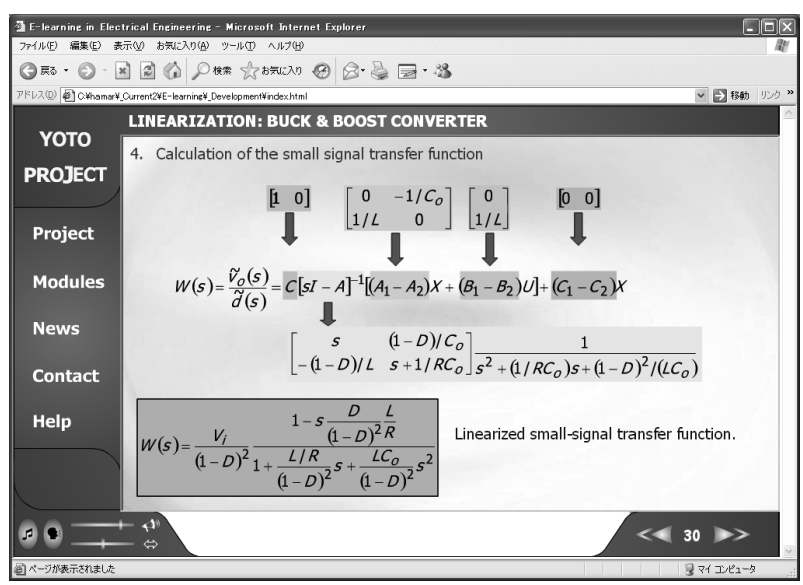

Fig. 6. Screens on practical use of linear modeling at the buck \& boost converter

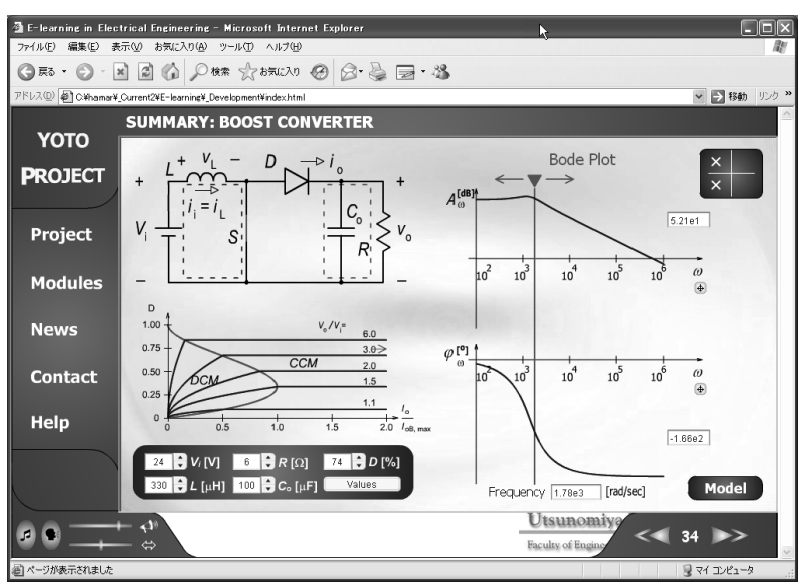

Fig. 7. Interactive modeling tools

(Fig. 7). The relative position of the steady-state operation point in the operation domain can also be traced after clicking on the "Characteristics" button (Fig. 7).

The switch in the converter strives to turn on and off proportionally to the duty ratio adjusted. The path of the current in the converter is also shown both in continuous and discontinuous conduction modes. On the right side of the screens the graphical representations of the models are indicated. User can select between the pole-zero map and the Bode plot of the system. In either case the plots are updated immediately for any modification of the system parameters. It facilitates a good insight into the dynamic behavior of the converter and helps in the interpretation of the dynamic model.

Switching among the plots is available by clicking on the button on the upper right side. In case of the Bode plot, by moving the vertical red guide left and right, the values of the frequency, magnitude and phase angle are displayed in the corresponding white text boxes. The pole-zero map is devoted to give insight how the poles and the zeros of the system are wandering as the parameters are being varied.

The discrete-time iterative mapping approach is discussed also for the case of continuous conduction mode on the basis of (11). The aim is to model the dynamics in a discrete manner over a switching period. The nonlinear system equations are shown in Fig. 8 as a start-up to the model development. 


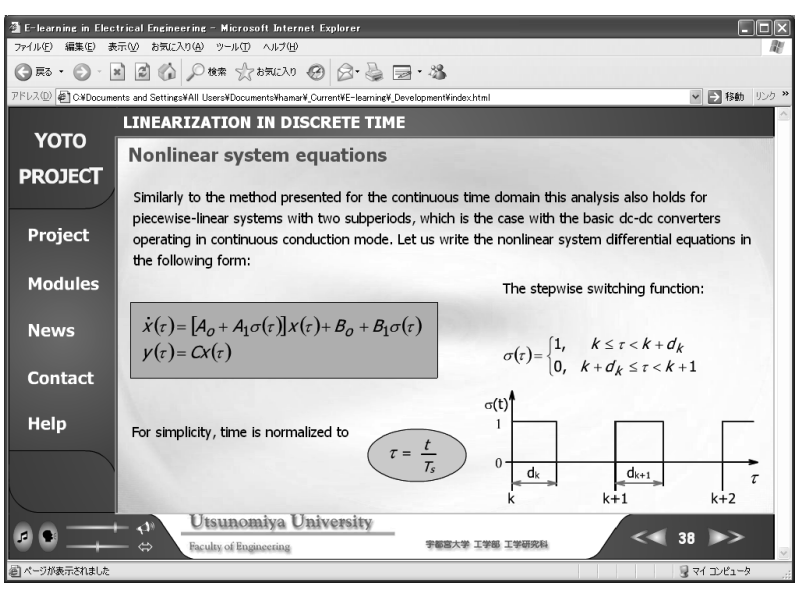

Fig. 8. Nonlinear system equations, periods and subperiods

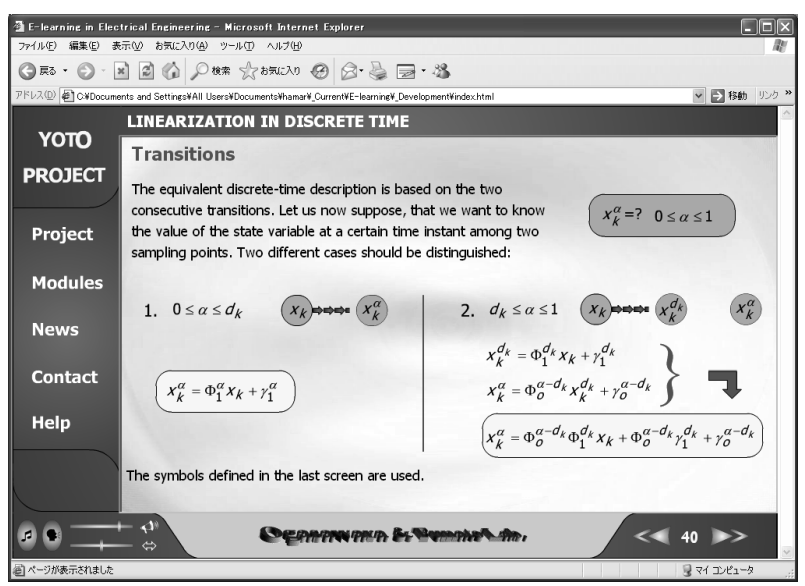

Fig. 9. Transitions among the sampling instants

The nonlinearity is implemented in the system equations by introducing the two-state, stepwise switching function $\sigma(\tau)$. It results in the strict separation of the switchingdependent and switching-independent dynamic components in the system equations via matrices $A_{0}, A_{1}, B_{0}$ and $B_{1}$. The sampling rate of the discrete system is equal to the switching frequency. The next step is the definition of the equivalent system, that is, the discrete time description of the original continuous-time system based on the transition from the $k$-th state to the $k+1$-th state. The equivalent discrete time description is based on two consecutive transitions, $x_{k} \rightarrow x_{k}^{d_{k}} \rightarrow x_{k+1}$, where $x_{k}^{d_{k}}$ is the switching instant in the $k$ th period.

The equivalent description also facilitates the retrieval of the instantaneous values among the sampling points. The transitions and the corresponding equations in the subperiods are indicated in Fig. 9.

After summarizing the results, the equivalent discrete time description is obtained. From dynamical point of view it is identical with the original continuous-time system. The next step is the linearization of the discrete time model around the stationary operation point (Fig. 10).

It practically means that the nonlinear terms are substituted by the partial derivatives calculated for the operation point. The origination of the Z-domain transfer function is also shortly summarized.

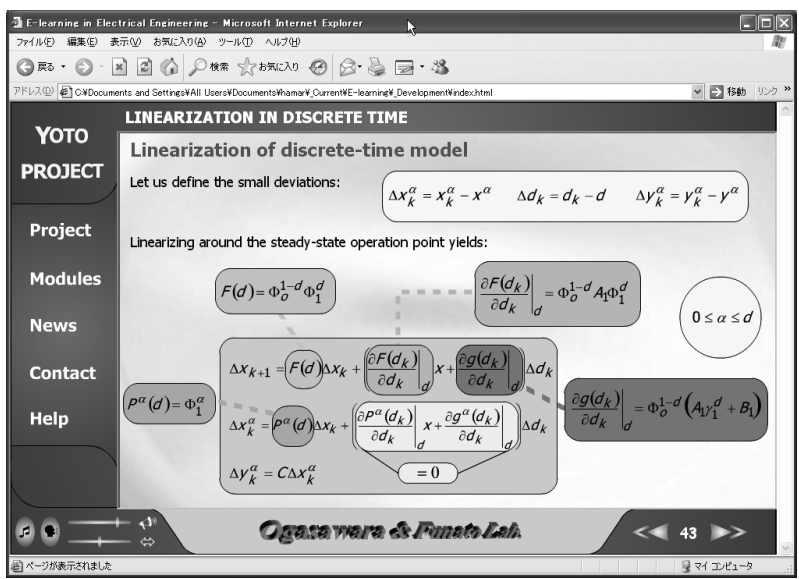

Fig. 10. Linearization of discrete-time model
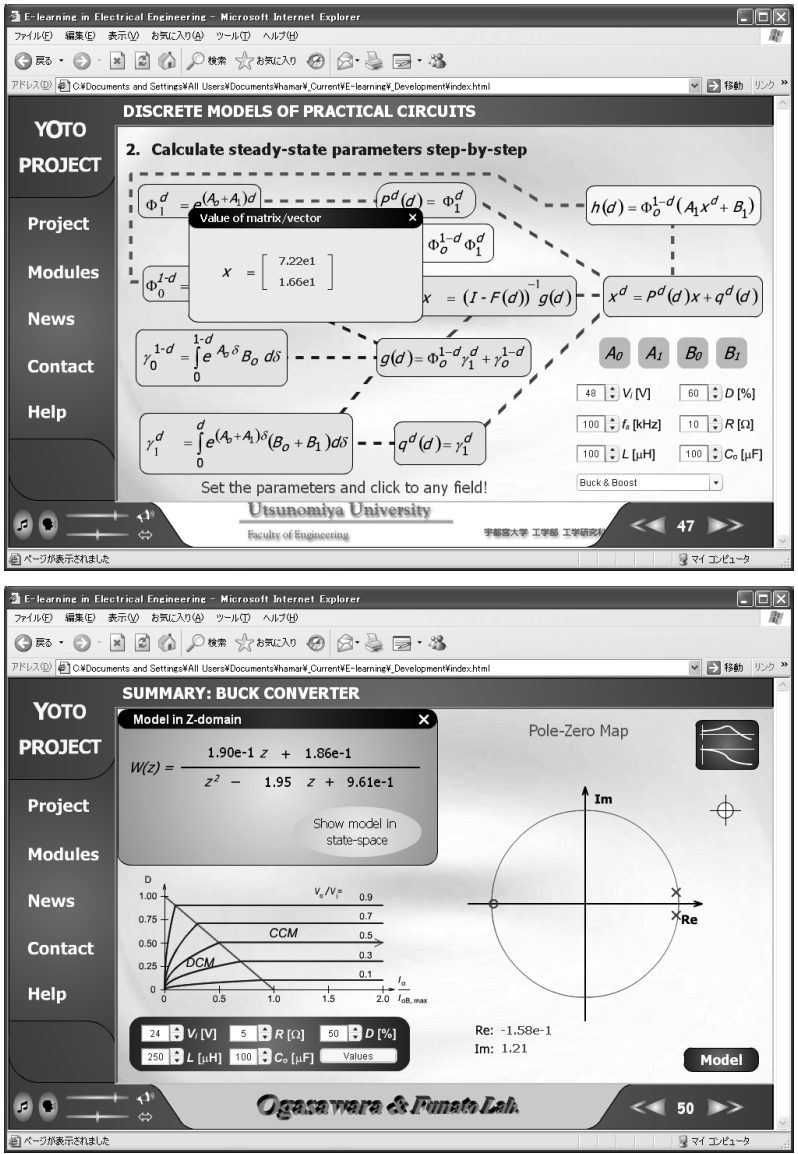

Fig. 11. Interactive calculation (a) and modeling (b) tools

After presenting the discrete-time modeling process, interactive calculation and modeling tools appear to support fast modeling and evaluation of the converters (Fig. 11). The linear models as matrices in state-space and as transfer functions in the Z-domain are automatically calculated and shown on the basis of the adjusted input and system parameters. Furthermore the discrete-time dynamic model obtained can be visualized by both pole-zero map and Bode-plot.

\section{Nonlinear Dynamics (Inetele Project)}

The e-learning software in this area contains two chapters concerning the linear and nonlinear dynamics. All screens 


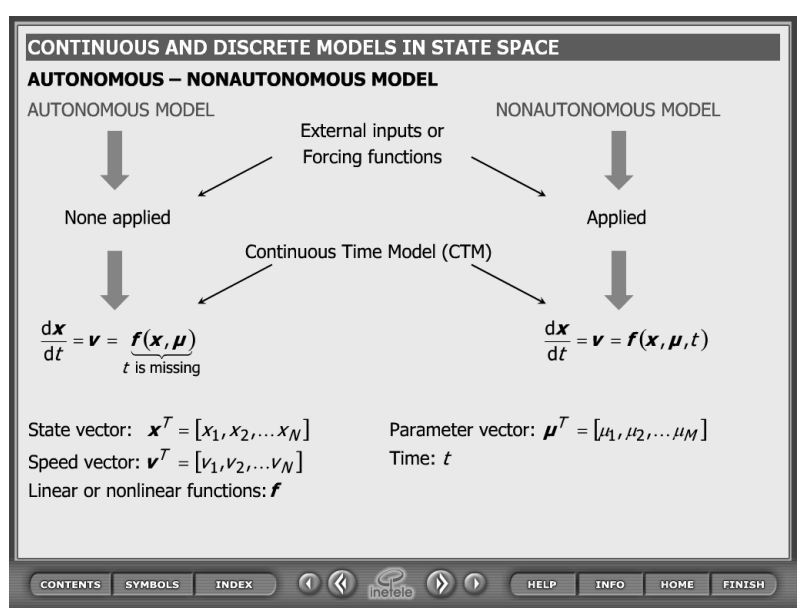

Fig. 12. Autonomous and non-autonomous model

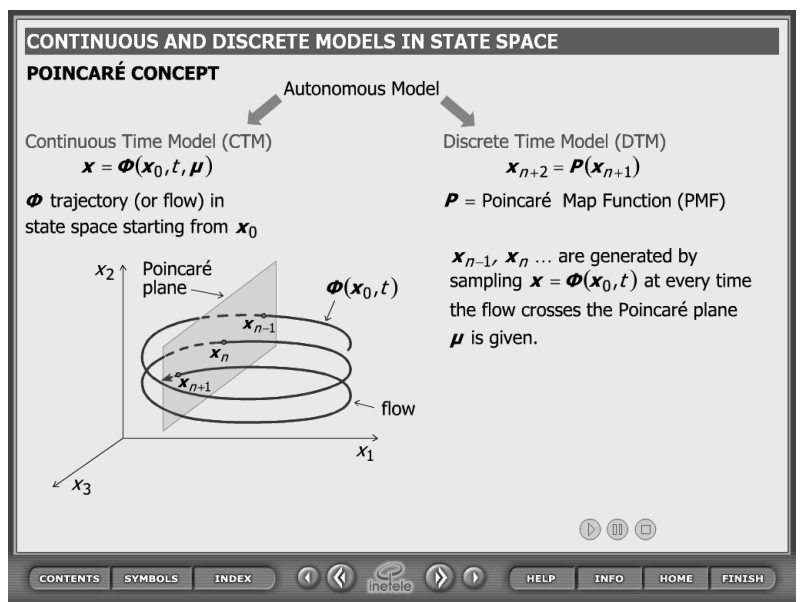

Fig. 13. Poicaré map-Autonomous Model

shown here were taken from the Nonlinear Part. Its main sections are: Continuous and Discrete-time Models in State Space, Regular States, Quasi-periodic State, Maps, Manifolds, Homoclinic and Heteroclinic Orbits, Bifurcations, Routes to Chaos, Chaotic State, Applications to Power Electronics.

3.1 Continuous and Discrete-Time Models in StateSpace Nonlinear systems can be classified by autonomous and non-autonomous models (Fig. 12). In the first (second) case, external inputs or forcing functions are not applied (are applied).

The dynamical systems are described by differential equations (Fig. 12) in the continuous time domain (CTM). Function $\mathbf{f}$ is linear (nonlinear) for linear (nonlinear) systems.

Fig. 13 contrasts the continuous time model (CTM) with the discrete time model (DTM) and introduces the Poincaré map for autonomous systems as well. The solution of the differential equation system gives the trajectory $\boldsymbol{\Phi}\left(\mathbf{x}_{\mathbf{0}}, \mathrm{t}, \boldsymbol{\mu}\right)$ describing the time evolution in state space (Fig. 13, where dimension $\mathrm{N}=3$ is assumed). $\mathbf{x}_{\mathbf{0}}$ is the initial condition. By initiating the animation, the trajectory $\boldsymbol{\Phi}$ is being drawn starting from $\mathbf{x}_{\mathbf{0}}$ and intersects the Poincaré plane from one direction at $\mathbf{x}_{\mathbf{n}-\mathbf{1}}, \mathbf{x}_{\mathbf{n}}$ and $\mathbf{x}_{\mathbf{n}+\mathbf{1}}$. The selection of the Poincaré plane is arbitrary. The only requirement to be fulfilled is that the trajectory has to cross the Poincaré plane transversally.

In place of continuous function $\boldsymbol{\Phi}\left(\mathbf{x}_{\mathbf{0}}, \mathrm{t}, \boldsymbol{\mu}\right)$ the Poincaré

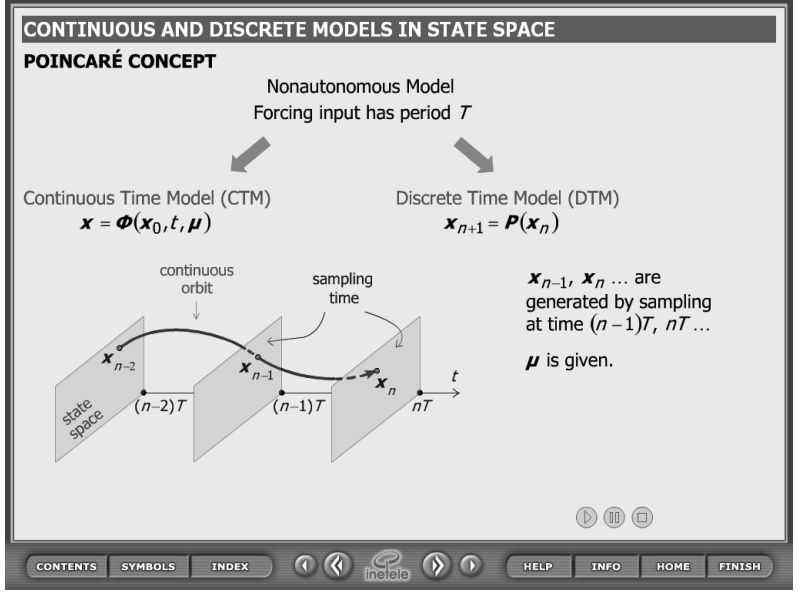

Fig. 14. Poincaré concept-Non-Autonomous Model

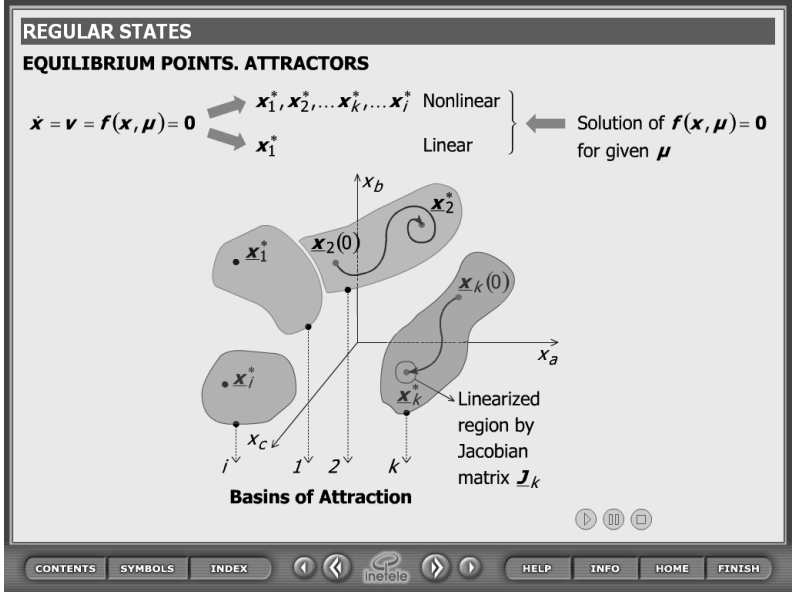

Fig. 15. Equilibrium points and attractors

map function (PMF) $\mathbf{x}_{\mathbf{n}}=\mathbf{P}\left(\mathbf{x}_{\mathbf{n}-1}\right)$ can be used, or in other words the CTM can be replaced by the discrete time model (DTM). PMF can be derived from the intersection points and it provides the relation between the consecutive intersection points e.g. $\mathbf{x}_{\mathbf{n}}$ and $\mathbf{x}_{\mathbf{n}-\mathbf{1}}$.

Fig. 14 contrasts CTM with DTM and presents the Poincaré map for non-autonomous systems. The continuous orbit is being drawn starting from point $\mathbf{x}_{\mathbf{n}-2}$ at time $(n-2) \mathrm{T}$ where $\mathrm{T}$ is the period of the forcing function. The next sampling time is $(n-1) T$, that is, period $T$ later at point $\mathbf{x}_{\mathbf{n}-\mathbf{1}}$. One period later the continuous orbit is at point $\mathbf{x}_{\mathbf{n}}$. The Poincaré map function is $\mathbf{x}_{\mathbf{n}}=\mathbf{P}\left(\mathbf{x}_{\mathbf{n}-\mathbf{1}}\right)$.

3.2 Regular States There are two regular states of nonlinear systems: the equilibrium points and the limit cycles.

Equilibrium Points One of the regular states is the equilibrium point. Fig. 15 repeats the differential equations in the case when the speed of the state variables $\mathbf{v}=0$, i.e. the system is in standstill. The nonlinear equation $\mathbf{f}(\mathbf{x}, \boldsymbol{\mu})=0$ can have large number of solutions $\mathbf{x}_{\mathbf{1}}{ }^{*}, \mathbf{x}_{\mathbf{2}}{ }^{*}, \ldots \mathbf{x}_{\mathbf{k}}{ }^{*}, \ldots \mathbf{x}_{\mathbf{i}}{ }^{*}$ and they depend on the system parameter vector $\mu$.

The final state of the autonomous system is determined by the initial condition. If the initial condition is $\mathbf{x}_{\mathbf{2}}(0)\left(\right.$ or $\left.\mathbf{x}_{\mathbf{k}}(0)\right)$, that is, if the initial point is in basin of attraction 2 (or in basin of attraction $\mathrm{k}$ ), the final state will be $\mathbf{x}_{\mathbf{2}}{ }^{*}$ or $\mathbf{x}_{\mathbf{k}}{ }^{*}$, which is also in the basin of attraction 2 (or in basin of attraction $\mathrm{k}$ ). 


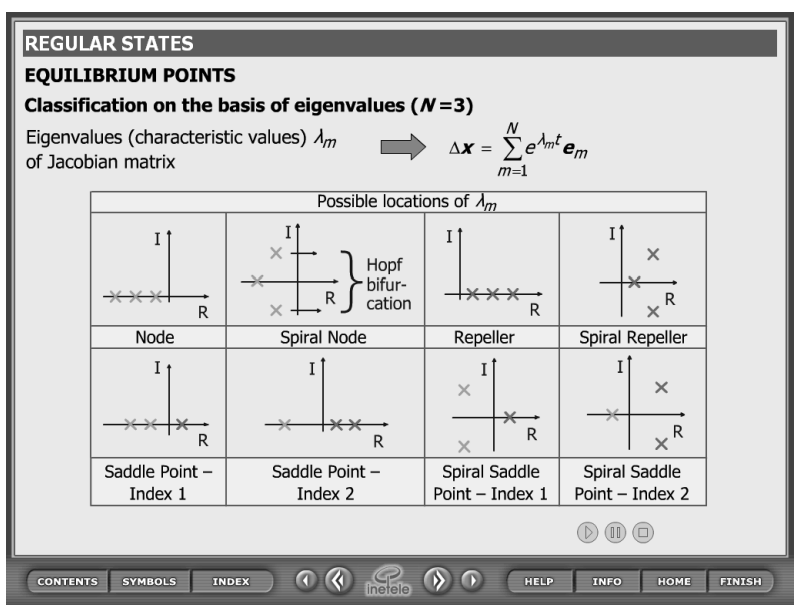

Fig. 16. Classification of eigenvalues

By starting the animation, a trajectory is being drawn from $\mathbf{x}_{\mathbf{2}}(0)$ to $\mathbf{x}_{\mathbf{2}}{ }^{*}$ (or from $\mathbf{x}_{\mathbf{k}}(0)$ to $\mathbf{x}_{\mathbf{k}}{ }^{*}$ ) (Fig. 15). Assuming that the matrix function $\mathbf{f}(\mathbf{x} ; \boldsymbol{\mu})$ can be differentiated in the close neighborhood of the equilibrium point $\mathbf{x}_{\mathbf{k}}{ }^{*}$, the differential equation system can be linearized by calculating the Jacobian matrix $\mathbf{J}_{\mathbf{k}}$ of $\mathbf{f}(\mathbf{x}, \boldsymbol{\mu})$.

Depending on the location of the eigenvalues $\lambda$ of the Jacobian matrix $\mathbf{J}_{\mathbf{k}}$ in the complex reference frame the equilibrium point can be stable or unstable. The condition for stability is that all real parts of the eigenvalues must be negative. The eight possible cases for dimension $\mathrm{N}=3$ are summarized in Fig. 16. By clicking on any of the names as Node or Repeller etc., the respective three crosses marking the location of the eigenvalues start twinkling.

The real parts of all eigenvalues are negative and the imaginary parts are zero for a node or two of them are nonzero for a spiral node. The node and spiral nodes are stable fixed points. The real parts of all eigenvalues are positive and the imaginary parts are zero for a repeller or two of them are nonzero for a spiral repeller. Either one or two of the real parts of the three eigenvalues are positive and all imaginary parts are zero for a saddle point. Finally, two out of the three eigenvalues are complex conjugate pair and either one or two eigenvalues are in the right side of the complex plane for a spiral saddle point. The trajectories approaching to and diverging from the equilibrium point are shown in the figures of the module. Trajectories heading directly toward and away from saddle point form the so-called stable (because $\operatorname{Re}[\lambda]<0$ along those trajectories) and unstable manifold, respectively. The manifolds divide the state-space into regions.

All trajectories but the manifolds belong to one of the regions and they are confined to their own region. Note that one or two directions of the eigenvectors are always stable (or unstable) in the saddle points.

Fig. 17 presents the trajectories for the three cases having conjugate complex eigenvalues $(\mathrm{N}=2)$. They are: 1.) $\operatorname{Re}\left[\lambda_{1,2}\right]<0$ focus attractor; 2.) $\operatorname{Re}\left[\lambda_{1,2}\right]>0$ focus repeller. 3.) $\operatorname{Re}\left[\lambda_{1,2}\right]=0$ center. By starting the animation, the trajectories are being plotted from their initial points. The last animated figure in the chapter Equilibrium Points shows the general case $\mathrm{N}>3$ (Fig. 18). Any of the eigenvalues of the Jacobian matrix of the equilibrium point $\mathbf{x}_{\mathbf{p}}$ can be either pure

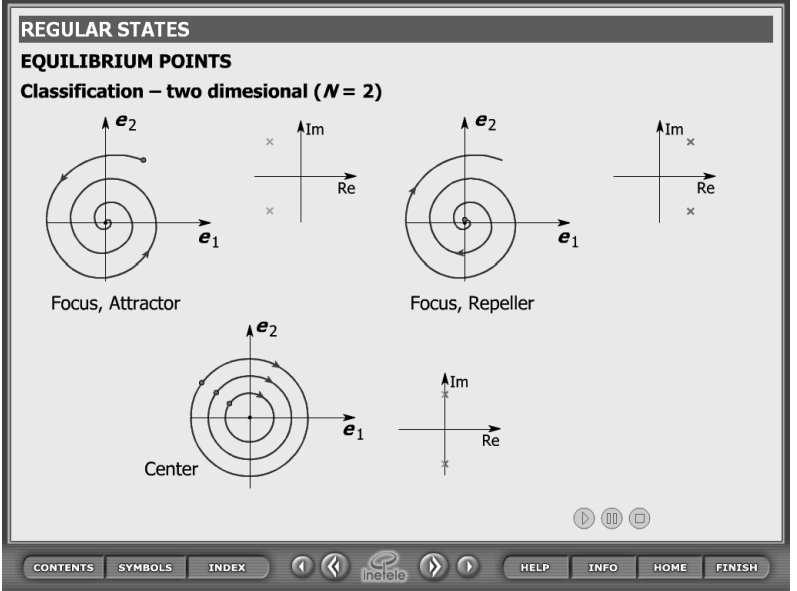

Fig. 17. Classification-two dimensional

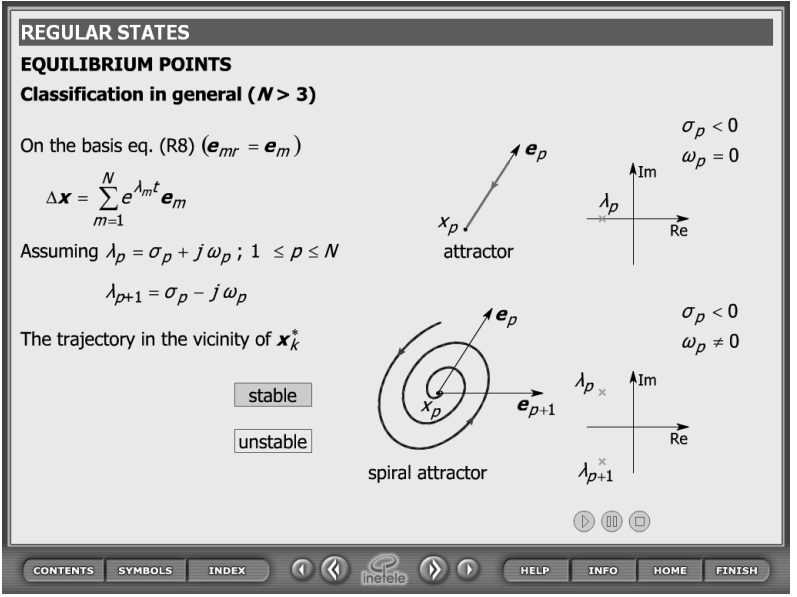

Fig. 18. Classification-in general

real or complex conjugate.

By selecting the stable (unstable) button in Fig. 18, and turning on the animation the eigenvalues appear on the left (right) side of the complex reference frame, and $\operatorname{Re}\left[\lambda_{\mathrm{p}}\right]=$ $\sigma_{\mathrm{p}}<0\left(\operatorname{Re}\left[\lambda_{\mathrm{p}}\right]=\sigma_{\mathrm{p}}>0\right)$. When $\operatorname{Im}\left[\lambda_{\mathrm{p}}\right]=\omega_{\mathrm{p}}=0$ a line is being drawn along the eigenvector $\mathbf{e}_{\mathbf{p}}$ approaching to (diverging from) the equilibrium point $\mathbf{x}_{\mathbf{p}}$. When $\operatorname{Im}\left[\lambda_{\mathrm{p}}\right]=\omega_{\mathrm{p}} \neq 0 \mathrm{a}$ spiral curve is being plotted in the plane of the two eigenvectors $\mathbf{e}_{\mathbf{p}}$ and $\mathbf{e}_{\mathbf{p}+\mathbf{1}}$ approaching to (diverging from) the equilibrium point $\mathbf{x}_{\mathbf{p}}$.

Limit Cycles Periodic state, the so-called limit cycle is possible in two or higher dimensional autonomous and, of course, in non-autonomous nonlinear systems. The trajectory keeps circulating along the same closed loop in steady-state. A question of paramount importance is whether the limit cycle is stable or not. The solution can be sought by pursuing the same procedure described above. However, Poincaré discovered a simpler and more elegant approach. It uses the concept of Poincaré section (PS) or map of limit cycle and Poincaré map function (PMF), introduced in section 3.1. The Poincaré section is a set of points in the Poincaré plane (hyperplane when the dimension of state-space is higher than three, $\mathrm{N}>3$ ) produced by the trajectory by piercing through the surface from one direction (Fig. 19).

The selection of Poincaré plane is arbitrary. The discrete Poincaré map function (PMF) relates the coordinates of point 


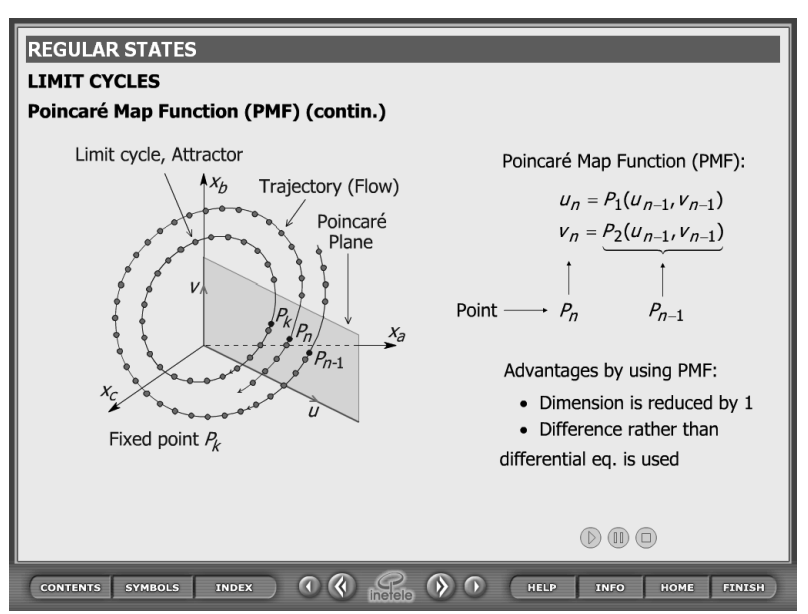

Fig. 19. Limit cycles

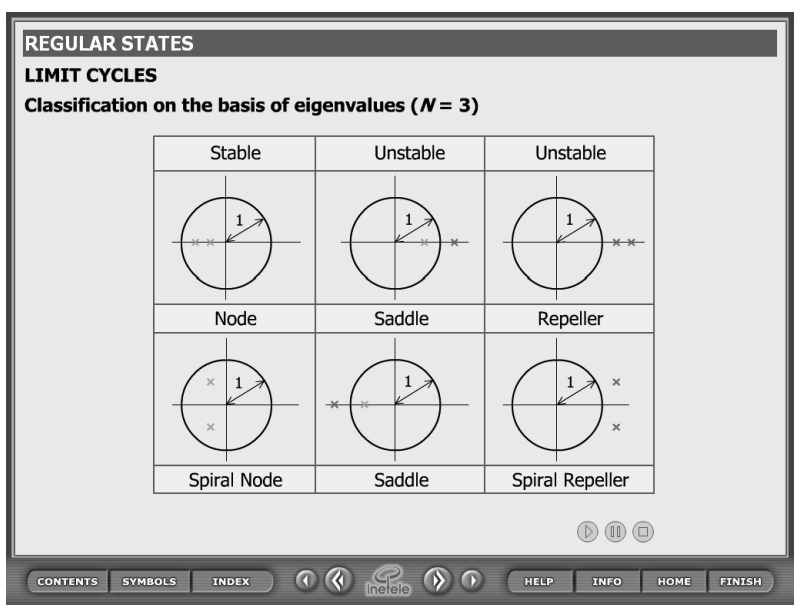

Fig. 20. Classification on the basis on eigenvalues

$\mathbf{P}_{\mathbf{n}}$ to those of the previous point $\mathbf{P}_{\mathbf{n}-\mathbf{1}}$. All points are the intersection points in the Poincare plane generated by the trajectory. The benefit of applying the PMF is the reduction of the dimension by one and the substitution of the differential equation by difference equation.

The six possible combinations of the eigenvalues of the Jacobian matrix of PMF at fixed point are presented in Fig. 20. By changing one or more system parameters the eigenvalues can be shifted from the interior of unit circle to its border. A so-called bifurcation occurs if one (or two) eigenvalue leaves the unit circle. New state(s) develops. The five possible trajectories around the limit cycles are summarized in Fig. 21. Point $\mathbf{P}$ belongs to the limit cycle drawn by heavy line in all five cases. Forcing the trajectory to move by small deviation from the limit cycle, if the trajectories approach point $\mathbf{P}$ in an aperiodic (node) or spiral (spiral node) way, the limit cycle is stable. If the trajectories diverge from (repellor) or spiral around (spiral repellor) and are repelled from point $\mathbf{P}$, the limit cycle in unstable. Finally, the trajectories can approach point $\mathbf{P}$ in one direction and can diverge in other direction from point $\mathbf{P}$ (saddle point).

\section{Conclusion}

Recent results from the Yoto and Inetele projects, highlighting the efforts to develop multimedia-rich e-learning courses upon power electronics and nonlinear systems have

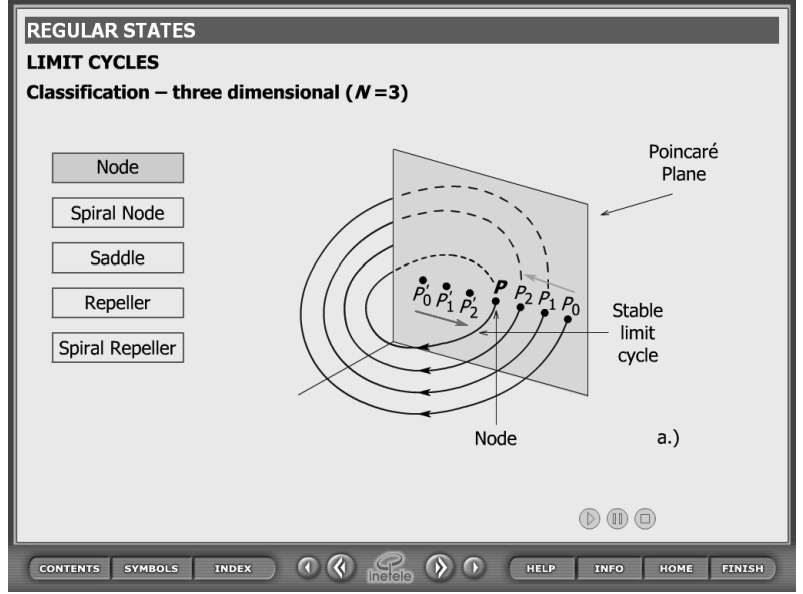

Fig. 21. Classification-three dimensional

been discussed. Topics about static and dynamic modeling of dc-dc converters were discussed in the first part in the frames of the Yoto project and the principles of nonlinear systems were presented in concert with the Inetele project in the second part. The software can be utilized in the university and industrial education and also supports the work of design and control engineers with fast, embedded software tools. They can be utilized as supplementary parts of virtual laboratories too.

\section{Acknowledgment}

The authors wish to thank the European Community program Leonardo da Vinci no 2002-CZ/02/B/F/PP-134009, the Hungarian Research Fund (OTKA T046240, F049152) and the Control Research Group of the Hungarian Academy of Science (HAS), the support stemming from the cooperation between HAS and the Japanese Society for the Promotion of Science (JSPS) and for the support of the Innovation Fund of Research and Technology in the frame of the scientific and technology cooperation between the Hungarian and Japanese Government. The authors would also like to thank the Computer and Automation Research Institute of the HAS, the Janos Bolyai Research Fellowship of the HAS as well as the Venture Business Laboratory (VBL) of the Utsunomiya University for the financial support.

(Manuscript received May 10, 2007,

revised Feb. 21, 2008)

\section{References}

(1) V. Fedak and P. Bauer: "E-learning in Education of Electrical Drives and Power Electronics: Opportunities and Challenges", International Conference on Electrical Drives and Power Electronics, 26-28 September, Dubrovnik, Croatia (2005)

( 2 ) U. Drofenik and J.W. Kolar: "Interactive Power Electronics Seminar (iPES)—A Web-Based Introductory Power Electronics Course Employing Java-Applets", Proceedings of the 33rd IEEE Power Electronics Specialists Conference, Vol.2, pp.443-448, Cairns, Australia, June 23-27 (2002)

( 3 ) Y. Nishida, U. Drofenik, and J.W. Kolar: "Interactive Animation Program for Power Electronics Education and Self-Learning”, Proceedings of the 2002 Annual Conference IEE Japan (in Japanese), Kagoshima, Japan, August 2123, CD-ROM (2002)

( 4 ) C.R. Sullivan: "Three dimensional animations of Power-Electronics Circuits visualize voltage and current", IEEE PESC 2003, Acapulco, pp.466-473, ISBN 0-78037759-9 (2003-6)

( 5 ) "Standardisation of Curriculum for Electrical Machines Using Multimedia", 
TEMPUS JEP CD-16127-2001 http://www.machines.cg.ac.yu/index.htm

( 6 ) http://www.sia.co.jp/ /icass/index.html

( 7 ) J. Hamar, H. Funato, S. Ogasawara, and I. Nagy: "New E-learning Tools for DC-DC Converters", European Conference on Power Electronics and Applications (EPE'2005), pp.P1-P10, ISBN: 90-75815-08-5, Dresden, Germany, September 11-14 (2005)

( 8 ) J. Hamar, R.K. Jardan, P. Korondi, I. Nagy, Z. Sepa, Z. Suto, K. Zaban, and H. Weiss: "Teaching and Learning Nonlinear Dynamics by Multimedia”, International Conference on Modeling and Simulation of Electric Machines, Converters and Systems (ELECTRIMACS'2005), CD ROM, ISBN 2-921145-51-0, Hammamet, Tunisia, April 17-20 (2005)

(9) P. Bauer and V. Fedak: "Educational Visualization of Different Aspects for Power Circuits and Electrical Drives", 11th International Power Electronics and Motion Control Conference, EPE-PEMC'2004, Riga, Latvia, 2-4 September (2004)

(10) J. Hamar, R.K. Jardan, I. Nagy, and H. Ohsaki: "Virtual Laboratory for Combined Solar Energy System", European Power Electronics and Drives Conference, EPE 2007, pp.1-8, ISBN: 9789075815108, Aalborg, Denmark, September 2-5 (2007)

(11) W.L. De Koning, J.W. Van Der Woude, and Y. Fuad: "Discrete-time modeling and analysis of pulse-width-modulated switched power converters", Electronic Proceedings of 15th International Symposium on the Mathematical Theory of Networks and Systems, University of Notre Dame, South Bend, Indiana, USA, August 12-16, 2002. Editors: D.S. Gilliam, J. Rosenthal.

(12) D. Boroyevich, F.C. Lee, and Q. Liu: "A Hands-on Professional Short Course Example: Modeling and Control Design of DC-DC Converters", IPEC'2005, pp.751-756, Niigata, Japan, April 4-8 (2005)

(13) K. Rigbers, S. Schroder, T. Durbaum, M. Wendt, and R.W. De Doncker: "Integrated Method for Optimization of Power Electronic Circuits", 35th Annual IEEE Power Electronics Specialists Conference, PESC'2004, pp.4473-4478, Aachen, Germany, June 20-25 (2004)

(14) C. Fernández, O. García, J.A. Cobos, and J. Uceda: "Self learning Laboratory Set up for Teaching Power Electronics Combining Simulations and Measurement", International Conference EPE-PEMC'2002, Cavtat \& Dubrovnic, Croatia.

(15) H. Hoyer, A. Jochheim, Ch. Rohrig, and A. Bischoff: "A Multiuser VirtualReality Environment for a Tele-Operated Laboratory", IEEE Transactions on Education, Vol.47, No.1 (2004-2)

(16) A. McGettrick, M.D. Theys, D.L. Soldan, and P.K. Srimani: "Computer Engineering Curriculum in the New Millennium", IEEE Transaction on Education, Vol.46, No.4 (2003-11)

(17) H. van der Broeck: "Students build their own Switched Mode Power Supplies or how to promote Power Electronics at Universities", International Conference EPE 2001, pp.P.1-P.9, Graz, Austria

(18) K. Rigbers, S. Schroder, T. Durbaum, M. Wendt, and R.W. De Doncker: "Integrated Method for Optimization of Power Electronic Circuits", 35th Annual IEEE Power Electronics Specialists Conference, PESC'2004, pp.4473-4478, Aachen, Germany, June 20-25 (2004)

(19) Mohan, Undeland, Robbins: "Power Electronics, Converters, Applications and Design", John Wiley \& Sons, 2nd Edition (1995) (ISBN 0-471-58408-8)

(20) H.H.C. Iu and C.K. Tse: Bifurcation Behaviour of Parallel-Connected Buck Converters, IEEE Transactions on Circuits and Systems I, Vol.48, No.2, pp. 233-240 (2001-2)

(21) S. Iyasu, T. Shimizu, and K. Ishii: "A Novel Iron Loss Calculation Method on Power Converters Based on Dynamic Minor Loop", International Conference EPE'2005, ISBN: 90-75815-08-5, pp.P1-P10, Dresden, Germany, September 11-14 (2005)

(22) I. Vajk and J. Hetthessy: Identification of Nonlinear Errors-In-variables Models. Automatica, Vol.39, Issue 12, pp.2099-2107 (2003)
Janos Hamar (Non-member) received his M.Sc. and Ph.D. degrees

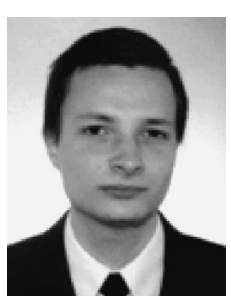
at the Budapest University of Technology and Economics in 1998 and 2002, respectively. His main research topic is related to power electronics conversion and control, software development for power electronics, e-learning and virtual laboratories. In 2002 he worked for the German company Exendis Industrie-Automation in Freiburg as development engineer. Between 2003 and 2004 he worked as sales manager of the DataM Electronics Ltd. In 2004, he returned to the Budapest University of Technology and Economics and got a senior lecturer position. In the same year he accepted an invitation to the Utsunomiya University Japan and worked there as research fellow until 2006. Dr. Hamar has about 40 technical papers published in international journals and conference proceedings. Professional memberships: IEEE, John von Neumann Computer Society, Hungarian Fuzzy Association and earlier IEE Japan.

István Nagy (Non-member) graduated from the Technical University

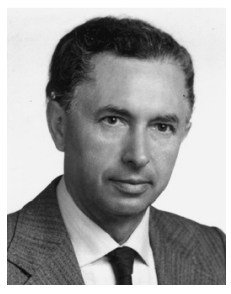
of Budapest, Hungary, in 1953. He received the Ph.D. degree from the same university in 1960. He has been associated with the Institute of Automation and Computation of the Hungarian Academy of Sciences since 1960, and Headed the Department of Power Electronics there for 15 years. He became a full professor at the Technical University of Budapest in 1975. He was a visiting professor at universities in Sweden, Germany, India, New Zealand, Italy, Canada, USA and Japan. His research interests are power electronics, control of ac drives and nonlinear dynamics. He is author or co-author of 14 textbooks, around 250 technical papers and 13 patents. He is a member of the Hungarian Academy of Sciences, chairman of EPE-PEMC council and member of the Hungarian IEE, EPE and IEEE Fellow. Member of AdCom of IES and PES of IEEE.

Hirohito Funato (Member) was born on Feb. 26th 1964 in

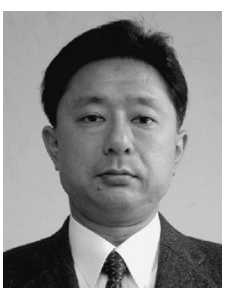
Fukushima, Japan. He received B.E., M.E. and Ph.D. degrees in electrical engineering from Yokohama National University, Japan in 1987, 1989, 1995 respectively. He worked at Tokyo Electric Power Company during 1989 to 1991 . He joined the faculty of engineering, Utsunomiya University in 1995 where he is now an associate professor. His research fields include application of power electronics to power system, digital control of power electronic circuits, renewable energy and so on. He received the PCC2007 Best Paper Award in 2007 and the IEEJ Paper Presentation Awards in 1994 and 1997. Dr. Funato is a member of IEEE PELS, IAS, IES.

Satoshi Ogasawara (Member) was born in Kagawa Prefecture,

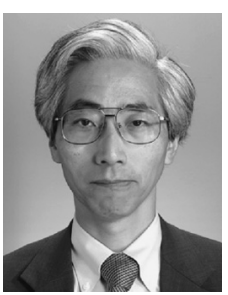
Japan, in 1958. He received the B.S., M.S., and Ph.D. degrees in electrical engineering from Nagaoka University of Technology, Niigata, Japan, in 1981, 1983, and 1990, respectively. From 1983 to 1992, he was a Research Associate at Nagaoka University of Technology. From 1992 to 2007, he was an Associate Professor in the Department of Electrical Engineering, Okayama University, Okayama, Japan. Since 2007, he has been a Professor in the Graduation School of Information Science \& Technology, Hokkaido University, Sapporo, Japan. His research interests are ac motor drive systems and static power converters. Dr. Ogasawara received the 1998 IEEE TRANSACTIONS ON POWER ELECTRONICS Prize Paper Award and three IEEE Industry Applications Society Committee Prize Paper Awards. He is a member of the Institute of Electrical Engineers of Japan and a Senior Member of the Institute of Electrical and Electronics Engineers. 
Octavian Dranga (Non-member) was born in Oradea, Romania in

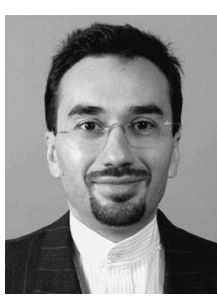
1971. He received the B.Eng., M.Sc. and Ph.D. degrees in Control Engineering from the "Politehnica" University of Timisoara, Romania in 1995, 1996 and 2001, respectively. He was with the same University, as an Assistant Lecturer, from 1996 to 1998. During 1998-2001, he was a Ph.D. student at the Budapest University of Technology and Economics, Hungary. He held postdoctoral positions with the Hong Kong Polytechnic University (2001-2002 and 2004-2005),

University of Hull, U.K. (2003) and Utsunomiya University, Japan (20032004). He has been a Lecturer in Electrical and Computer Engineering at James Cook University, Australia, since January 2006. His research interests are in the study of nonlinear phenomena in power electronics, e-learning and distributed power generation. He has authored 50 technical publications.
Yasuyuki Nishida (Member) was born in Japan on October 19, 1956.

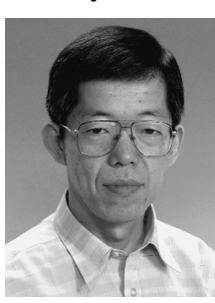
He studied Electrical Engineering at undergraduate course of Nihon University, and Power Electronics at master course of Tokyo Denki University. Then, he received his Ph.D. in Electrical Engineering from Yamaguchi University in 1998. Since 1998 he has been with Nihon University in Japan, and his is currently an Associate Professor in the department of Electrical \& Electronic Engineering in the University. He has stayed in Swiss Federal Institute of Technology (ETH) Zurich from April to September 2006 as a visiting researcher. The focus of his current research is on single-phase and three-phase PFCs including "Passive and Hybrid PFCs", "Current-Source-Type PWM PFCs". and "TOKUSADA rectifier". He also has been interested in PE Education tools and systems. He is a member of the IEEJ, IEEE, EPE and JIPE. He had been serving as the vice-chair of Technical Program Committee of PCC-Nagoya-2007, an advisory board member of international conference on PCIM and a member of other international conferences. 